\title{
Fabrikasi Lapisan Antirefleksi dengan Bahan Methyl Methacrylate (MMA) Menggunakan Metode Spin Coating
}

\author{
Sudarsono, Gatut Yudoyono, Bachtera Indarto, Yono Hadi Pramono, Faridawati \\ Jurusan Fisika, FMIPA Institut Teknologi Sepuluh Nopember Surabaya \\ Kampus ITS, Keputih Sukolilo 6011 Jawa Timur, Indonesia \\ *Sudars29@gmail.com,**gyudoyono@physics.its.ac.id
}

\begin{abstract}
Abstrak - Telah dilakukan fabrikasi lapisan antirefleksi dengan bahan methyl methacrylate dengan metode spin coating. Lapisan methyl methacrylate dilapiskan pada substrat kaca kemudian diputar dengan kecepatan 1000 rpm dengan metode spin coating. Untuk membuat lapisan anti refleksi dibutuhkan indeks bias substrat lebih besar dari pada lapisan film, sehingga salah satu bahan yang dipilih pada penelitian ini adalah methyl methacrylate dengan indeks bias 1,49. Dari hasil fabrikasi didapatkan nilai ketebalan lapisan adalah 10,816 $\mu \mathrm{m}$. karakterisasi hasil fabrikasi dilakukan menggunakan spektrometer UV Vis dengan panjang gelombang (390-450) $\mathrm{nm}$ dan menghasilkan transmisi lebih dari $87,842 \%$ dan absorbsi kurang dari 0,056 \%. Dari hasil transmisi dan absorbsi bahan tersebut maka hasil refleksi relatif kecil sehingga dapat digunakan sebagai lapisan antirefleksi.
\end{abstract}

\begin{abstract}
Fabrication of anti-reflection coating is performed by methyl methacrylate material with spin coating method. Methyl methacrylate layer is coated on glass substrate is then rotated at a speed of 1000 rpm with spin coating method. To make anti-reflection coating substrates required refractive index greater than the film so one of the materials used in this study is methyl methacrylate with a refractive index of 1.49. Coating thickness values obtained as the results of this fabrication is $10.836 \mu \mathrm{m}$. Characterization of the fabrication result is done by using UV Vis spectrometer with wavelength (390-450) $\mathrm{nm}$ and producing transmission more than $87.842 \%$ and absorption less than $0.056 \%$. From the results of the transmission and absorption so the reflection result is relatively small so it can be used as an anti-reflection coating.
\end{abstract}

Key words: non reflecting coating, spin coating, methyl methacrylate

\section{PENDAHULUAN}

Dalam kehidupan sehari-hari tidak bisa lepas dari cahaya, tanpa cahaya maka dunia ini akan menjadi. Cahaya merupakan gelombang elektromagnetik yang dapat merambat tanpa medium perantara. Kecepatan rambat cahaya di ruang hampa sebesar $3 \times 10^{8} \mathrm{~m} / \mathrm{s}$. Banyak fenomena cahaya yang sering kita jumpai dalam kehidupan sehari-hari diantaranya peristiwa pemantulan, pembiasan, polarisasi, interferensi[1]. Dari beberapa fenomena tersebut banyak dilakukan kajian dan penelitian tentang fenomena cahaya. Pada penelitian ini dilakukan penelitian tentang fenomena interferensi cahaya khususnya pada lapisan tipis dimanfaatkan sebagai lapisan anti refleksi. Lapisan antirefleksi banyak dimanfaatkan sebagi lapisan tambahan pada alat optik seperti kaca mata, sehingga kaca mata menjadi lebih nyaman ketika dipakai[2]. Salah satu untuk membuat kacamata menjadi nyaman adalah dengan membuat lapisan pada lensa kacamata yang berfungsi sebagai antirefleksi. Secara konsep fisika lapisan pada kacamata tesebut dapat dipandang sebagai lapisan tipis. Pada lapisan tipis terjadi fenomena cahaya yaitu peristiwa interferensi, dengan memanfaatkan peristiwa interferensi maka dapat ditentukan jenis dan tebal lapisan tipis sehingga dapat menjadi lapisan yang dapat berfungsi sebagai antirefleksi. Lapisan anti refleksi yang sering digunakan adalah bahan $\mathrm{MgF}_{2}$, namun bahan tersebut sulit didapatkan dan harganya mahal. Pada penelitian ini akan dibuat lapisan anti refleksi dengan bahan Methyl Methacrylate dengan metode spin coating [3].

\section{LANDASAN TEORI}

Peristiwa interferensi merupakan hasil perpaduan antara dua gelombang atau lebih yang bertemu pada satu titik didalam ruang dan menimbulkan fenomena fisik yang dapat diamati. Interferensi pada lapisan tipis dapat diamati dalam kehidupan sehari-hari misalnya pada air yang berisi lapisan minyak di atasnya terlihat berwarna. Untuk menimbulkan interferensi dibutuhkan sumbersumber gelombang (cahaya) yang bersifat koheren yaitu gelombang yang mempunyai frekuensi sama dan beda fase tetap dalam perambatannya[4]. Dalam konteks koheren dikenal dengan temporal coherence yang berhubungan dengan waktu dan spatial coherence yang 
berhubungan dengan jarak. Salah satu cara untuk mendapatkan dua sumber cahaya koheren adalah dengan pantulan dari seberkas sinar berasal dari sumber cahaya[4 5]. Dalam peristiwa interferensi ada interferensi saling menguatkan (terang) dan interferensi saling melemahkan (gelap) seperti ditunjukkan pada Gambar 1[2,3,6-8],
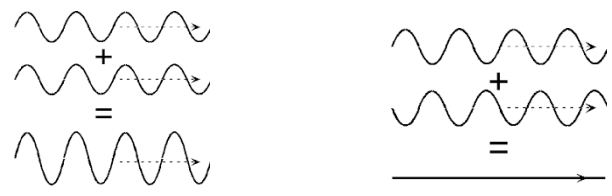

a. Saling menguatkanb.

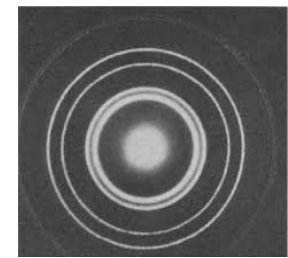

c. pola yang diamati

Gambar 1. Pola interferensi

\section{Non Reflecting Film}

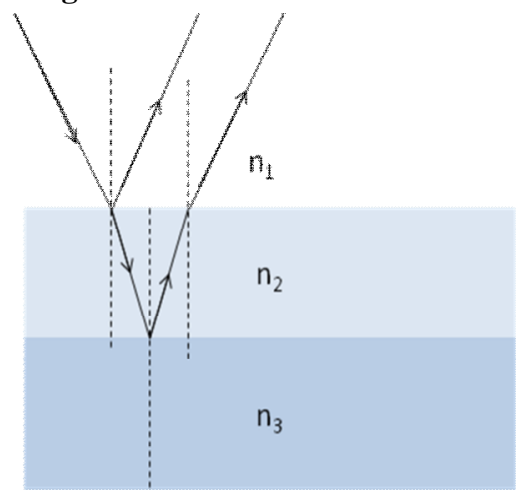

Gambar 2. lapisan nonreflecting

Peristiwa non reflecting film misalnya sekeping gelas di atasnya dilapisi dengan suatu bahan yang indeks biasnya antara udara dan keeping gelas. Lapisan ini bersifat sebagai pemantul yang menghasilkan 2 sinar pantul dari permukaan atas dan bawah. Sinar yang langsung dipantulkan pada permukaan pertama mempunyai beda fase $\pi$ dan sinar yang dipantulkan oleh permukaan kedua juga berbeda fase $\pi$ [4 5]. Maka kedua sinar tersebut akan menghasilkan interferensi maksimum dan minimum. Untuk pola maksimum mengikuti pola [4]

$$
2 n d=2(m+1) \lambda
$$

Dan

$$
\begin{aligned}
& \text { untuk pola minimum mengikuti } \\
& 2 n d=(2 m+1) \frac{1}{2} \lambda
\end{aligned}
$$

untuk minimum . Pada saat interferensi minimum, berarti keping tak tampak dari atas dan tebal lapisan paling kecil adalah jika $\mathrm{m}=0$ atau $d=\frac{1}{4 n} \lambda$ dengan $\mathrm{n}$ adalah indeks bias lapisan. Pola gelap berikutnya adalah

$d=\left(\frac{1}{4}\right) \frac{\lambda}{n},\left(\frac{3}{4}\right) \frac{\lambda}{n},\left(\frac{5}{4}\right) \frac{\lambda}{n}, \ldots \ldots . .(2 m+1) \frac{\lambda}{n}$

Peristiwa antirefleksi terjadi bila $\mathrm{n}_{1}<\mathrm{n}_{2}<\mathrm{n}_{3}$ dimana $\mathrm{n}_{1}$ adalah indeks bias udara, $\mathrm{n}_{2}$ indeks lapisan dan $\mathrm{n}_{3}$ indeks bias keping gelas[5,6,9]. Skema penggambaran dari interferensi pada lapisan antirefleksi untuk single layer dapat dilihat pada Gambar 3 [10].

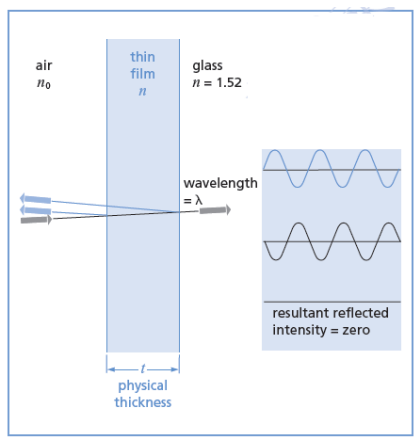

Gambar 3. Interferensi pada lapisan anti refleksi single layer [10]

\section{METODE PENELITIAN}

Pada penelitian ini bahan-bahan yang digunakan adalah kaca slide mikroskop sebagai substrat methyl methacrylate (MMA) sebagai bahan pembuat lapisan tipis serta sabun tepol dan alkohol untuk memebersihkan substrat dari kotoran yang menempel pada permukaannya. Peralatan yang digunakan seperangkat alat spin coater yang digunakan untuk proses pelapisan lapisan tipis, mikroskop yang digunakan untuk pengamatan dan menentukan ketebalan lapisan tipis. Preparasi substrat dilakukan dengan memotong kaca preparat dengan ukuran panjang $2 \mathrm{~cm}$ dan lebar $1 \mathrm{~cm}$. Langkah awal setelah substrat dipotong terlebih dahulu permukaan samping substrat diratakan dengan amplas ukuran 240, 360, 500, 800, 1500 dan 2000, kemudian substrat dibersihkan, dicuci menggunakan aceton lalu dikeringkan menggunakan hair dryer. Proses ini dilakukan berulang-ulang sampai dipastikan bahwa substrat benar-benar bersih.

Setelah pembuatan larutan berhasil lagkah selanjutnya adalah pembuatan lapisan tipis dengan mengguankan alat spin coating. Lapisan tipis berupa MMA dengan kecepatan putar $1000 \mathrm{rpm}$, lapisan tipis yang terbentuk dipanasi dengan suhu $80^{\circ} \mathrm{C}$ selama 5 
menit dan didiamkan selama 12 jam agar pelarut menguap. Langkah selanjutnya melakukan pengamatan lapisan tipis dengan menggunakan mikroskop

Untuk mengetahui lima lapisan yang terbentuk maka lapisan diamati dengan menggunakan mikroskop yang telah dilengkapi dengan detektor optik, serta dihubungkan dengan komputer.

Sifat optis berupa besaran absorpsi, dan transmisi diamati menggunakan perangkat spectrometer UV-Vis, dengan rentang panjang gelombang 390-450 nm.

\section{HASIL DAN PEMBAHASAN}

Pada gambar 4a menunjukkan hasil fabrikasi substrat yang tepinya belum digosok dengan ampelas sehingga kelihatan tidak rata, maka perlu diratakan terlebih dahulu dengan ampelas. Hasil substrat yang sudah diratakan dengan ampelas namun belum dilapisi dapat ditunjukkan pada gambar 4b. Tujuan pengamplasan adalah agar lapisan dapat menyebar merata pada substrat dengan baik sehingga mempermudah pengamatan lapisan yang terbentuk.
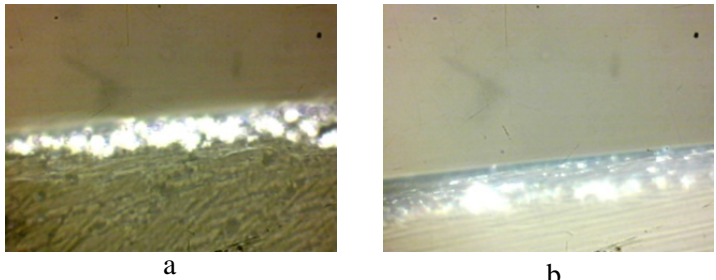

Gambar 4. hasil fabrikasi substrat

Gambar 5a menunjukkan struktur antirefleksi yang akan difabrikasi dengan substrat berupa kaca dengan lapisan berupa MMA. Sedangkan pada gambar 5b menunjukkan hasil fabrikasi antirefleksi.

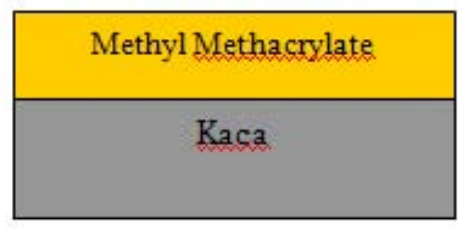

a

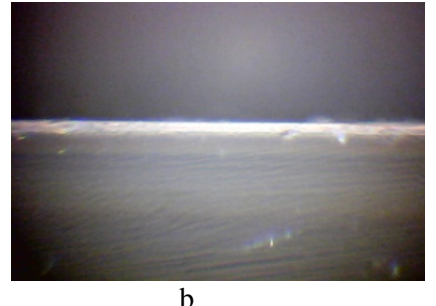

Gambar 5. Struktur lapisan antirefleksi
Pengukuran ketebalan dilakukan dengan cara membuat perbandingan skala pixel dengan skala mikrometer. Penentuan skala pixel adalah dengan menggunakan persamaan 1.[7]

$$
1 \text { pixel }=\frac{\text { shift }}{\text { pixel } 1-\text { pixel } 2}
$$

dengan

pergeseran : besarnya pergeseran pada mikrometer

pixel 1 : posisi gambar sebelum digeser

pixel 2 : posisi gambar setelah digeser perhitungan jarak antar pixel adalah seperti ditunjukkan Tabel 1.
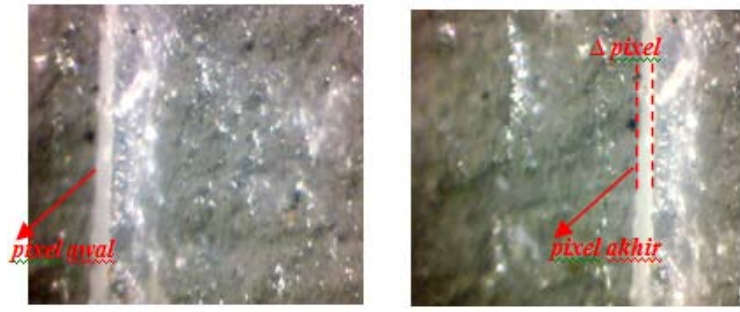

Gambar 6. sampel (a) sebelum digeser, (b) setelah digeser

Tabel 1 Hasil perhitungan jarak 1 pixel

\begin{tabular}{lcccl}
\hline No & $\begin{array}{c}\text { Pegeseran } \\
(\mathrm{mm})\end{array}$ & $\begin{array}{c}\text { Pixel } \\
\text { awal }\end{array}$ & $\begin{array}{c}\text { Pixel } \\
\text { akhir }\end{array}$ & $\begin{array}{l}\text { Jarak 1 pixel } \\
(\mathrm{mm})\end{array}$ \\
\hline 1 & 0.01 & 254 & 314 & 0.000167 \\
2 & 0.01 & 314 & 370 & 0.000178 \\
3 & 0.01 & 370 & 424 & 0.000185 \\
4 & 0.01 & 424 & 486 & 0.000161 \\
5 & 0.01 & 486 & 552 & 0.000152 \\
\hline
\end{tabular}

Dari data dalam Tabel 1, maka rata-rata untuk jarak 1 pixel adalah

$$
\begin{aligned}
1 \text { pixel } & =\frac{0.000167+0.000178+0.000185+0.000161+0.000152}{5}=0.000169 \mathrm{~mm} \\
& =0,169 \mu \mathrm{m}
\end{aligned}
$$

setelah diketahui 1 pixel adalah 0,169 $\mu$ m, maka digunakan untuk mengukur ketebalan lapisan film dengan persamaan :

$$
\begin{aligned}
\text { tebal } & =\Delta \text { pixel } \times 0.169 \mu \mathrm{m} \\
& =(320-256) \times 0.169 \mu \mathrm{m} \\
& =10,816 \mu \mathrm{m}
\end{aligned}
$$

Untuk perhitungan ketebalan hasil fabrikasi ditunjukkan dengan kecepatan $1000 \mathrm{rpm}$ adalah sebesar 10,836 $\mu \mathrm{m}$. Hasil pengujian dengan spektrometer UV Vis untuk absorbsi dan transmisi ditunjukkan Gambar 7 dan 8 . 


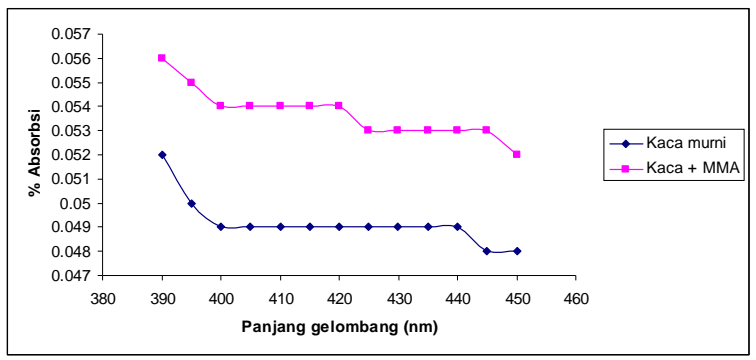

Gambar 7. hasil uji Absorbsi

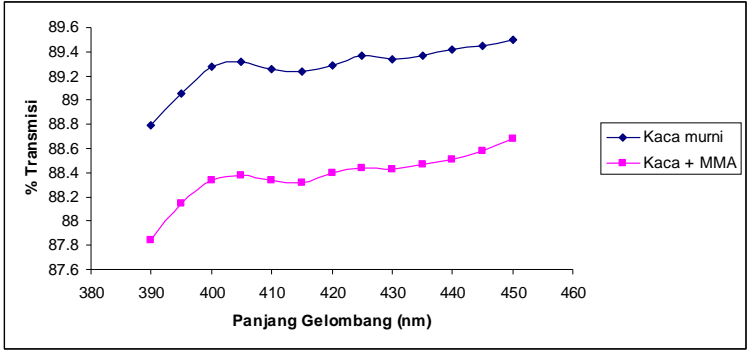

Gambar 8. hasil uji transmisi

Dari hasil uji transmisi dan absorbsi dengan menggunakan spekrometer UV Vis dengan rentang panjang gelombang $390 \mathrm{~nm}$ sampai $450 \mathrm{~nm}$ seperti terlihat pada gambar 7 dan 8 menunjukkan bahwa transmisi lebih dari $87,842 \%$ dan absorbsi kurang dari $0,056 \%$, sehingga reflektansi dari bahan hasil lapisan tipis dengan bahan MMA dan substrat kaca relatif kecil. Karena hasil refleksi tersebut relatif kecil maka material tersebut dapat dimanfaatkan sebagai salah satu material antirefleksi. Material antirefleksi dapat dimanfaatkan sebagai lapisan dalam alat optik seperti kacamata. Pada pemakai kacamata yang lensanya tidak memiliki lapisan antirefleksi mereka akan merasa silau akibat dari pantulan cahaya (yang tidak diinginkan) dari permukaan lensa. Namun dengan memberikan lapisan antirefleksi hal itu tidak lagi terjadi. Dengan lapisan antirefleksi lensa mampu mentransmisikan cahaya hampir $100 \%$ ke mata sehingga pemakai kacamata akan melihat lebih tajam dan kontras selain terhindar dari silau [3]. Selain itu dengan melapiskan lapisan antirefleksi pada kacamata maka hasil pemotretan Orang yang menggunakan antirefleksi pada kacamatanya akan terlihat seolah - olah tidak menggunakan lensa kacamata dan membuat tampilan foto lebih indah[10].

\section{KESIMPULAN}

Dari hasil fabriaksi dan karakterisasi lapisan tipis MMA dengan metode spin coating dapat disimpulkan lapisan mempunyi ketebalan 10,816 $\mu \mathrm{m}$ dengan transmisi lebih dari $87,842 \%$ dan absorbsi kurang dari $0,056 \%$. Dari hasil transmisi dan absorbsi trsebut maka hasil refleksi dari lapisan tipis dengan bahan MMA dan substrat kaca relatif kecil sehingga dapat difungsikan sebagai lapisan antirefleksi.

\section{PUSTAKA}

[1] E. Hecht, "Optics", $4^{\text {th }}$ edition, Addison-Wesley Publishing Company, New York (2001)

[2] Kavakli, pek Girgin, " Single and Double-Layer Antireflection Coatings on Silicon, Turk J Phys, vol 26 ,349-354, (2002)

[3] J. T. Cox and G. Hass, "Antireflection coatings for optical and infrared materials" Physics of Thin Films,eds. G. Hass and R. E. Thun, vol. 2 (Academic Press, New York, 1968) p.239

[4] Frank and Leno, "Introduction to Optics", Prentice -Hall Internasional, second editon, (1993)

[5] Guenter R, “ Modern Optics” John Welly \& Sons, Inc, (1990)

[6] Jenkins and White, "Fundamental of Optics", Four Edition, McGraw Hill, (1957)

[7] Rinawati, "Fabrication and Characterization Directional coupler Slab Structure Based on Polystyrene and Polymethyl Methacrylate (PMMA) Polimer, Thesis, ITS, 2009

[8] Serway, R. A., Jewwet, John, W.," Physics For Scientist And Engineers $6^{\text {th }}$ Edition". Harcourt Brace \& Company. Florida (2004)

[9] G. H. Sherman and P. D. Coleman, Appl.Opt.,10, (1971), 2675.

[10] A. Musset and A. Thelen, "Multilayer antireflection coatings" in Progress in Optics, ed. E.Wolf, vol. VIII (North-Holland Publ.Co., Amsterdam, 1970) .203 